another episode in which her catatonia and fever improved with ECT. The younger daughter also had an episode of fever and autonomic instability without rigidity with no neuroleptics. (Castillo suggested that muscle rigidity may be absent in lethal catatonia). These cases could be diagnosed as lethal catatonia rather than NMS.

Drs Dalkin \& Kennedy, and Drs White \& Robins, stated that the two conditions are indistinguishable on clinical grounds and the pathophysiologies are similar, although others (Castillo et al, 1989; Fleischhacker et al, 1990) attempted to differentiate between the two conditions. Fleischhacker believes that many patients, having been started on neuroleptics, diagnosed as NMS, might actually have been lethal catatonia. Is it possible that we are diagnosing the same condition that was first described by Calmeil in 1832 and numerous times thereafter as NMS when neuroleptics are prescribed, and as lethal catatonia when they are not?

Drs Otani et al mentioned in their paper that they could not find any reports on familial NMS in the literature. Stauder, in his original description of lethal catatonia, reported a family history of catatonia, including lethal catatonia, in half of his 27 cases.

Castillo, E., Rubin, R. \& Holsber Traschler, E. (1989) Clinical differentiation between lethal catatonia and malignant neuroleptic syndrome. American Journal of Psychiatry, 146, 324-328.

FLeischHACKER, W. W., UNTERWENGER, B., KANE, J. M., et al (1990) The neuroleptic syndrome and its differentiation from lethal catatonia. Acta Psychiatrica Scandinavica, 81, 3-5.

Stauder, K. H. (1870) Die todliche katatonie. Archiv fur Psychiatrie und Nervenkrankheiten, 102, 614-634.

T. K.S. TAN

Department of Psychological Medicine

National University Hospital

Singapore

St Mary Abbots Hospital

S. H. ONG

London W8 $5 L Q$

\section{Psychiatrists and citizens}

SIR: Dr Jim Birley's Presidential Address of July 1990, reproduced in the Journal (July 1991, 159, 1-6) is elegant, erudite, eloquent and timely.

At the first William Sargant Lecture, in July 1991, in the presence of Dr Sargant's widow, Dr Birley, in giving the vote of thanks to the speaker, chose to recall, as risible, Dr Sargant's objection to the Modecate study as unethical (Hirsch et al, 1973). This was a study carried out at the Institute of which Dr Birley was dean. The consent of the patients was neither sought nor obtained, the families were not informed and the general practitioners not asked to approve. Sixty-six per cent of the patients on placebo relapsed.

What makes Dr Sargant's observance of the "God given condition of eternal vigilance" a matter for levity, if not scorn? Does not Dr Sargant's action more appropriately "Deserve the love and thanks of man and woman"? (Paine, 1778).

Is there a price to be paid for thinking that 'eternal vigilance' begins at home?

Hirsch, S. R., Gaind, R., Rohde, P. D., et al (1973) Outpatient maintenance of chronic schizophrenic patients with long acting fluphenazine: double-blind placebo trial. British Medical Journal. $i, 633-637$.

Paine, T. (1778) Crisis.

12 Castle Garden

Gerald Samuel

Petersfield

Hampshire GU32 3AG

\section{Frégoli transformed}

SIR: We read with interest the report by O'Sullivan \& Dean (Journal, August 1991, 159, 274-277) of four cases of the Frégoli delusion occurring in puerperal illnesses. Previous references in the literature to delusional misidentification in this setting mentioned only the Capgras type (e.g. De Leo et al, 1985).

However, the descriptions of the patients, as reported, do not correspond to the classic one of Courbon \& Fail. The hallmark of the Frégoli phenomenon is the delusional misidentification of familiar persons disguised as others. By our reading, all four cases could have exhibited the phenomenologically related, but much rarer, intermetamorphosis delusion, which refers to the conviction that a key person has been physically transformed into another. Of course, patients often show an admixture of symptoms, which may make the exact delineation of phenomenology something of an exercise in sophistry.

Over the last seven decades, a plethora of mutually incompatible, psychodynamic explanations, reflecting the imagination and conceptual frameworks of individual authors, have been invoked to account for the Capgras and other delusions of misidentification. However, as Guze (1988) has succinctly pointed out, the psychotherapeutic process is intrinsically incapable of establishing the causal basis of psychopathology, and aetiological hypotheses generated during therapy are therefore of doubtful validity unless tested critically outside this situation. Of course, this does not imply that psychosocial factors do not play a part in the development of the content of such delusions - what remains to be proven is that such factors are necessary and sufficient. 
We therefore question the importance Drs O'Sullivan \& Dean attach to ambivalence arising with childbirth in the pathogenesis of their patients' delusional beliefs. By their account, at least three of the four patients were, premorbidly, well adjusted individuals, and all eventually made a satisfactory recovery. No corroborating evidence is offered to support the authors' hypothesis and no allowance is made for the possibility that the content of the delusions might have been a clinical manifestation of the psychotic illness itself rather than a special clue to its aetiology. A more plausible and parsimonous explanation, at the level of both phenomenology and understanding, would be in terms of their patients' attempts to make sense of a world perceived as disturbed, thereby entering or escaping into what appears to be a delusional interpretation of events. There are important implications too, particularly if it is assumed that delusional misidentification is basically a love-hate conflict, resolved by directing ambivalent feelings to an imagined double, and that successful treatment requires the person implicated to change his or her attitude towards the patient.

Finally, the authors note the risk of violence associated with delusional misidentification. Since the reviews by Fishbain (1987) and de Pauw \& Szulecka (1988), further reports have confirmed the potential danger such patients could pose to others (e.g. Driscoll et al, 1991), including political figures (Silva et al, unpublished).

De Leo, D., Galligioni, S. \& MAGn, G. (1985) A case of Capgras delusion presenting as a postpartum psychosis. Journal of Clinical Psychiatry, 46, 242-243.

De Pauw, K. W. \& Szulecka, T. K. (1988) Dangerous delusions: violence and the misidentification syndromes. British Journal of Psychiatry, 152, 91-96.

Driscoll, R., Chithiramohan, R. \& Brockman, B. (1991) Capgras syndrome, mania and delusionally motivated assaults. Journal of Forensic Psychiatry, 2, 49-57.

FishBain, D. A. (1987) The frequency of Capgras delusions in a psychiatric emergency setting. Psychopathology, 20, 42-47.

GuzE, S. B. (1988) Psychotherapy and the etiology of psychiatric disorders. Psychiatric Developments, 3, 183-193.

Department of Psychiatry

Karel de PauW

Doncaster Royal Infirmary

Doncaster DN2 SLT

Department of Psychiatry

KRYSTYNA SZULECKA

Bassetlaw District General Hospital

Worksop S81 OBD

\section{Promoting the correct use of psychotropic drugs}

SIR: I am a physician from Pakistan and have spent 20 years with the World Health Organization
(WHO) in Geneva trying to meet WHO objectives by assisting member states in co-operation with concerned United Nations agencies in promoting efforts to obtain maximum benefit from a pharmaceutical product and to prevent any harm the substance might be capable of producing. For the last 14 years I have concentrated on psychoactive substances.

I read with great interest the letter of the late Dr John Dunne (Journal, July 1991, 159, 156). Dr Dunne concluded that, although pharmacotherapy has made a major contribution to psychiatric treatment, it does not alleviate the need for the human therapeutic process. What he tells us is that valuable drugs can be discredited by misuse. I share his views entirely.

My work in the last 14 years, as Chief of Psychotropic and Narcotic Drugs was primarily to assess the benefit and risk ratio for psychoactive substances. In addition, I investigated the role a doctor, invariably in the company of a pharmacist and a nurse, can play in promoting the rational use of these drugs. A wide-ranging analysis of what can be done to reduce the misuse of psychoactive drugs without compromising appreciation of their therapeutic value is given by Ghodse \& Khan (1988). Their book is not only to help doctors but also their other equally important partners, i.e. pharmacists and nurses. It has been translated into many other languages, as well as English and French.

Another publication, The Rational Use of Psychoactive Drugs with Special Emphasis on Tranquillizers in Psychiatric Settings by Vartainen et al (1987) is based on a meeting debating the issues of use of psychotropic drugs in general medical practice. It was evident that the majority of doctors who prescribed these drugs were not psychiatrists. It was also believed that efforts to strengthen further medical education of doctors in rational prescribing was the key to the solution of the problems associated with their use. An interaction between psychiatrists and other specialists, as well as general medical practitioners, was considered essential.

At the second regional meeting of the Royal College of Psychiatrists which met in Islamabad, Pakistan in December 1990, I raised the issue that there is a need for the College to prepare written material for the guidance of general medical practitioners who prescribe psychotropic drugs more often than psychiatrists. I was assured that the College will seriously consider this proposal.

Thus the views of the late John Dunne are valuable and need to be seriously considered in all corners of the world.

Ghodse, H. \& KHAN, I. (1988) Psychoactive Drugs: Improving Prescribing Practices. Geneva: WHO. 